\title{
Towards an Integrated Curriculum in a Speech and Language Pathology Education Programme: Development and Constituents' Initial Responses
}

\author{
Sofia Strömbergsson ${ }^{a}$ Katarina Holm ${ }^{a}$ Anette Lohmander ${ }^{a, b}$ Per Östberg ${ }^{a, b}$

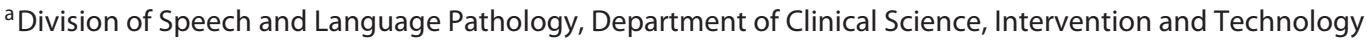 \\ (CLINTEC), Karolinska Institutet, Stockholm, Sweden; ${ }^{\mathrm{b}}$ Functional Area Speech and Language Pathology, \\ Karolinska University Hospital, Stockholm, Sweden
}

\section{Keywords}

Education · Linguistic skills · Logopaedics ·

Speech-language pathology $\cdot$ Undergraduates

\begin{abstract}
Background: A traditional curricular structure may challenge integration between foundational and clinical sciences in speech and language pathology (SLP) education. This project aimed to increase curriculum integration at a Swedish SLP education programme. Methods: Learning outcomes in the existent curriculum were copied from their original courses and re-structured with reference to vertical tracks, in order to address them within and across years of study. A content analysis of interviews with teachers and students was conducted for the evaluation of curricular change. $\boldsymbol{R e}$ sults: Among the changes were earlier introduction to clinical science and revisiting of foundational sciences later in the education. Theme concepts were defined to scaffold horizontal integration, whereas revisited use of documented material was formalized to ensure vertical integration. In
\end{abstract}

evaluation interviews, multiple examples were provided of how the new curriculum was perceived as being more integrated, with horizontal themes and vertical tracks providing structure. Concerns raised highlight the importance of appointing clear responsibilities. Conclusions: The concepts "gaps" and "overlaps" may guide remediation of areas where increased curricular integration is warranted. Serial child observations running through the curriculum may provide a platform for both horizontal and vertical integration. For maintenance of curricular integration, clear responsibilities are needed, stretching across course and semester boundaries.

(c) 2019 The Author(s)

Published by S. Karger AG, Basel

\section{Introduction}

In professional terms, practicing as a speech and language pathologist requires a wide range of knowledge and skills to master involvement in the prevention, assessment, intervention, management and scientific

\begin{tabular}{ll}
\hline KARGER & $\begin{array}{l}\text { (c) } 2019 \text { The Author(s) } \\
\text { Published by S. Karger AG, Basel }\end{array}$ \\
E-Mail karger@karger.com & $\begin{array}{l}\text { This article is licensed under the Creative Commons Attribution- } \\
\text { NonCommercial-NoDerivatives 4.0 International License (CC BY- }\end{array}$ \\
www.karger.com/fpl & $\begin{array}{l}\text { NC-ND) (http://www.karger.com/Services/OpenAccessLicense). } \\
\text { Usage and distribution for commercial purposes as well as any dis- } \\
\text { tribution of modified material requires written permission. }\end{array}$
\end{tabular}

Sofia Strömbergsson, PhD, SLP

Division of Speech and Language Pathology, CLINTEC

Karolinska Institutet, F67, Karolinska University Hospital, Huddinge

SE-141 86 Stockholm (Sweden)

E-Mail sofia.strombergsson@ki.se 
study of disorders of communication and swallowing in individuals of all ages $[1,2]$. In academic terms, speech and language pathology (SLP) is a multi-disciplinary field of knowledge, encompassing foundational sciences in psychology, linguistics and biomedicine, and sometimes education, as well as the theoretical and clinical science of communication and swallowing disorders [2]. As such, SLP education often involves teachers at different faculties and disciplines, fostered in different traditions and possibly with different presuppositions about the proper objectives of SLP training. In the traditional structure of SLP education programmes - as of medical education programmes in general - foundational science courses are given early in the education, followed by clinical science courses in later parts [3-5]. These two factors - the multi-disciplinary nature of SLP and the traditional curricular structure - may challenge educators ${ }^{1}$ who strive towards linking between foundational and clinical sciences [4], and students' appreciation of the relevance of foundational science to their later clinical practice $[6,7]$. In this paper, we describe the educational development of an SLP education programme, with the specific focus on increasing curriculum integration between foundational and clinical sciences.

\section{Curriculum Integration}

A long-standing trend towards more integrated curricula is reflected in many medical education programmes today, with a move towards earlier clinical application and the reconnection to foundational science at later stages in the education $[4,8]$. This linking between earlier and later courses in an education programme is often referred to as vertical integration [9]. The linking between different subject areas during the same contiguous block of time, on the other hand, is referred to as horizontal integration [9]. Although many educators strive towards curriculum integration, an operational definition of what constitutes an integrated curriculum is difficult to find [6]. It may be helpful, therefore, to approach the concept from an opposite view, with an illustration of unsatisfactory curriculum integration. An education where courses are delivered as isolated building blocks, with insufficient attention to progression and common denominators between subject areas, can be expected to result in gaps and overlaps between different

\footnotetext{
${ }^{1}$ Here and throughout, we use "teacher" when referring to individuals teaching, and "educator" when referring to individuals involved in curricular planning.
}

Towards an Integrated Curriculum in SLP courses. A gap could thus be the result of one course presuming knowledge that the students have not acquired before. An overlap would, on the other hand, be the result if a topic covered in one course is repeated, without extension or increasing complexity, in another course. An education designed to reflect both horizontal and vertical integration can instead be expected to show fewer gaps and overlaps. Whereas gaps are presumably unhelpful, overlaps are not necessarily negative and can instead be advantageous in a curriculum [6], by facilitating learning by repetition and highlight complementary academic aspects on a topic. However, while ensuring that students attain learning outcomes, it is important to identify and eliminate non-helpful overlaps to economize with time.

In the context of horizontal integration, problembased and case-based learning are often mentioned as remediating means $[9,10]$. A common denominator for such models is the thematic or conceptual point of excursion, where contributions from different subject areas are needed to solve or address a topic. More generally, a key to horizontal integration is designing curricula around themes, rather than around separate subject areas $[11,12]$. Whitehill et al. [10] describe a problem-based learning curriculum in an SLP education programme at the University of Hong Kong. Learning outcomes are structured thematically instead of course-based: foundations of speech, language and hearing sciences in the first year, and communication and swallowing disorders in the paediatric or in the adult population in the second and third year, respectively. Through early encounters with real-life clinically based problem cases, the students are expected to be active acquirers of knowledge, integrating content from different subject areas without the subject areas themselves determining the curricular structure [10]. The construction of knowledge, across subject areas, is an example of horizontal integration in SLP education.

Among strategies for vertical integration, "spiral curriculum" or "spiral learning" (introduced in [13], and subsequently used in, e.g., $[14,15])$ is a recurring concept. In a spiral curriculum, a topic or case can be presented early and intermittently revisited during the course of the education, processed by the students at increasingly advanced levels. By linking earlier to later parts of the education, spiral learning can thus be a way of implementing vertical integration. Howard and Heselwood [16] have illustrated how spiral learning may be implemented in SLP education, at the University of Sheffield. In their example, a video recording of an SLP therapy session is introduced 
in the first year of studies and revisited throughout the education, serving as a source to which the students apply their advancing transcription skills of speech and language disorders.

Within medical education in general, the SLP education is young, and published descriptions of curricular development within SLP education are still rare. From the descriptions that do exist, the above-mentioned trend towards problem-based learning curricula can be noted. Apart from this, SLP educational development focusing on bridging between theory and practice has also been described, for example by Hill et al. [17]. Undoubtedly, these descriptions offer valuable inspiration in the continuous development of SLP education and are also relevant to the concept of curricular integration in general. However, apart from the previously mentioned spiral curriculum model $[16,18]$, we are not aware of any previously published descriptions of SLP educational development specifically targeting the integration between foundational and clinical science in SLP.

\section{The SLP Education Programme in Sweden}

The SLP Programme in Sweden is a 4-year university programme, leading up to a 1-year master's degree. The education is multi-disciplinary and includes studies in SLP, psychology, linguistics, as well as biomedical courses and practicum in close collaboration with clinical departments at University Hospitals and County Councils. For a more detailed description of SLP education in Sweden and Scandinavia, see Söderpalm [3].

SLP education in Sweden has certainly evolved during the 50 years since it started but has basically retained a design where the first semesters are primarily devoted to foundational science courses in psychology, linguistics and biomedicine, while later semesters focus on applying this knowledge in clinical science SLP courses [3]. Administratively, courses within the SLP programmes are given not only at multiple departments within the medical faculty, but also at other faculties or even at other universities as well as at clinical departments. Hence, the education design stems not only from tradition, but also from the administrative challenges of bridging different departments and faculties.

The SLP education programme at Karolinska Institutet (henceforth: SLP-KI) shares an overall curricular structure both with other Swedish SLP education programmes and with traditional medical education programmes; foundational science courses are primarily given during the first 2 years of education, and clinical science courses (theoretical and practical) primarily during the final years. As such, concerns of unsatisfying curriculum integration that have been raised in the context of general medical education may also be raised for SLPKI.

Indeed, previous course evaluations within the programme have found both teachers and students reporting signs of gaps and overlaps in the SLP-KI curriculum. For example, when entering the first clinical science course in the education programme - children and youth with language disorders - students have reported feeling inadequately equipped with theoretical knowledge of typical speech and language acquisition, which they are expected to have achieved in earlier linguistics courses. This can be seen as an indicator of a gap between foundational and clinical science in the vertical dimension. Another example of a gap, but in the horizontal dimension, is indicated in the students' concerns regarding the stream Child Observations. This stream comprises activities where second-semester students recruit parents to a new-born infant and make recurring visits during two and a half years to report and discuss in small groups. The students' concerns regarding a lack of coordination between these activities with other courses given during the same time indicate unsatisfactory horizontal integration. An example of a curricular overlap is the students' reports of having had repeated introductions to the normal hearing mechanism of the ear - in courses in audiology, phonetics and voice and speech disorders. An additional, and more general, concern with the existent curriculum is that of students - at least in retrospect perceiving courses during the final 2 years as much more condensed compared to courses during the first 2 years. This indication of a workload imbalance between the early semesters (primarily devoted to foundational sciences) and the later semesters (primarily devoted to clinical sciences) is resonated in teachers' reporting of too little time for students' self-study during the final 2 years. Together, these examples illustrate unsatisfying curricular integration between foundational and clinical science in the existent SLP-KI education programme.

\section{Aim}

The overall aim of this project was to increase curriculum integration at the SLP-KI education programme between foundational and clinical science. The specific research question was:
Strömbergsson/Holm/Lohmander/ Östberg 
Table 1. The distribution of ECTS course credits across subject area and study year

\begin{tabular}{|c|c|c|c|c|c|}
\hline \multirow[t]{2}{*}{ Study year } & \multicolumn{3}{|c|}{ Foundational science } & \multicolumn{2}{|c|}{ Clinical science } \\
\hline & psychology & linguistics & biomedicine & SLP theory & SLP practice \\
\hline 1 & 22.0 & 27.0 & 8.0 & 3.0 & 0.0 \\
\hline 2 & 23.5 & 22.5 & 7.0 & 4.0 & 3.0 \\
\hline 3 & 0.0 & 0.0 & 7.5 & 30.0 & 22.5 \\
\hline 4 & 0.0 & 0.0 & 0.0 & 40.5 & 19.5 \\
\hline Total & 45.5 & 49.5 & 22.5 & 77.5 & 45.0 \\
\hline
\end{tabular}

The subject areas representing foundational science (psychology, linguistics and biomedicine) are also represented by different departments, whereas SLP science is represented by one department, but partitioned into SLP theory and SLP practice. European Credit Transfer and Accumulation System (ECTS) course credits are common across European universities; 60 ECTS credits correspond to 1 year of academic studies.

How do constituents involved in an SLP education programme (i.e., teachers, students and clinical representatives) experience a revised curricular structure of the programme?

\section{Materials and Methods}

Table 1 shows the original curricular structure of the SLP-KI, in terms of the distribution of credits across subject areas representing foundational sciences (psychology, linguistics and biomedicine) and clinical sciences (SLP theory and SLP practice). As the table shows, foundational sciences were primarily covered during the first 2 years and clinical sciences primarily during the last 2 years.

\section{Curriculum Change}

The curricular revision was led by the first author, who - at that time - was neither involved as a teacher nor as a student at the SLP-KI education programme. As a preparatory step, all learning outcomes were copied from the courses in which they originally appeared. Supposedly, this would untie the new structure from existent boundaries between courses, while maintaining the content of the education programme. In order to enable a curricular structure unrestricted by subject area (e.g., psychology, linguistics), six curriculum tracks were defined with inspiration from comparable SLP education programmes [10, 19], namely: Communication, Participation and Society, Research Methods, Biomedical Science, SLP Theory and SLP Practice. A spreadsheet was constructed, with the six tracks as columns, and an assumed timeline, reflecting progression, represented vertically. The spreadsheet thus provided new structure for the existent learning outcomes, enabling an overview unrestricted by previous compartmentalization based on subject areas (see Fig. 1).

The vertical imbalance between earlier and later parts of the education programme in terms of course credits across subject areas (Table 1) was also evident in terms of course content, as structured in the spreadsheet (Fig. 1). Here, learning outcomes relating to the track Communication were predominantly found during the first 2 years, whereas learning outcomes relating to the tracks SLP Theory and SLP Practice were predominantly found during the last 2 years. In spreadsheet terms, vertical columns were only partially filled with content throughout the course of the education programme. Imbalance was also evidenced horizontally, such that content was not spread across entire rows, i.e., across the different tracks. This imbalance is also reflected in Figure 1.

The observed imbalance was addressed by striving towards filling columns vertically (e.g., by revisiting the track Communication also in the later part of the education) and by identifying common themes horizontally. As an example, "Normality" was identified as a common denominator for many early learning outcomes across the different tracks. This theme could be tied to aspects of typical cognitive development (in the Communication track), to the statistical concept of normal distribution (in the Research Methods track), and to discussions around what signifies atypical communication (in the SLP Theory track). In order to further address horizontal integration, new learning outcomes were suggested that enabled use of same material across different tracks, for example re-using recordings collected for the purpose of practicing observation skills (in the SLP Practice track) in activities focusing on the acoustic analysis of child-directed speech (in the Communication track).

The suggested curricular structure was first presented at a meeting with SLP teacher staff at the department $(n=10$, of whom 4 were also clinicians), teachers from other departments $(n=12)$, as well as with clinical representatives $(n=2)$ and student representatives $(n=3)$ (clinical representatives served the double role of being both clinical supervisors and potential employers.) Participants were invited to comment and suggest adjustments, and discussions focused on grouping learning outcomes into courses, with the aim of setting the new course structure. Further discussions focused on suggesting learning activities designed to align with the suggested learning outcomes and/or to adjust the learning outcomes to match 
Fig. 1. Schematic illustration of the distribution of learning outcomes in the curriculum before the curricular changes, across the six vertical tracks Communication, Participation and society, Research methods, Medical science, SLP theory and SLP practice, and across the eight semesters of the education programme. Each box represents one learning outcome, with the restriction that the number of stacked boxes never exceeds seven, for readability.
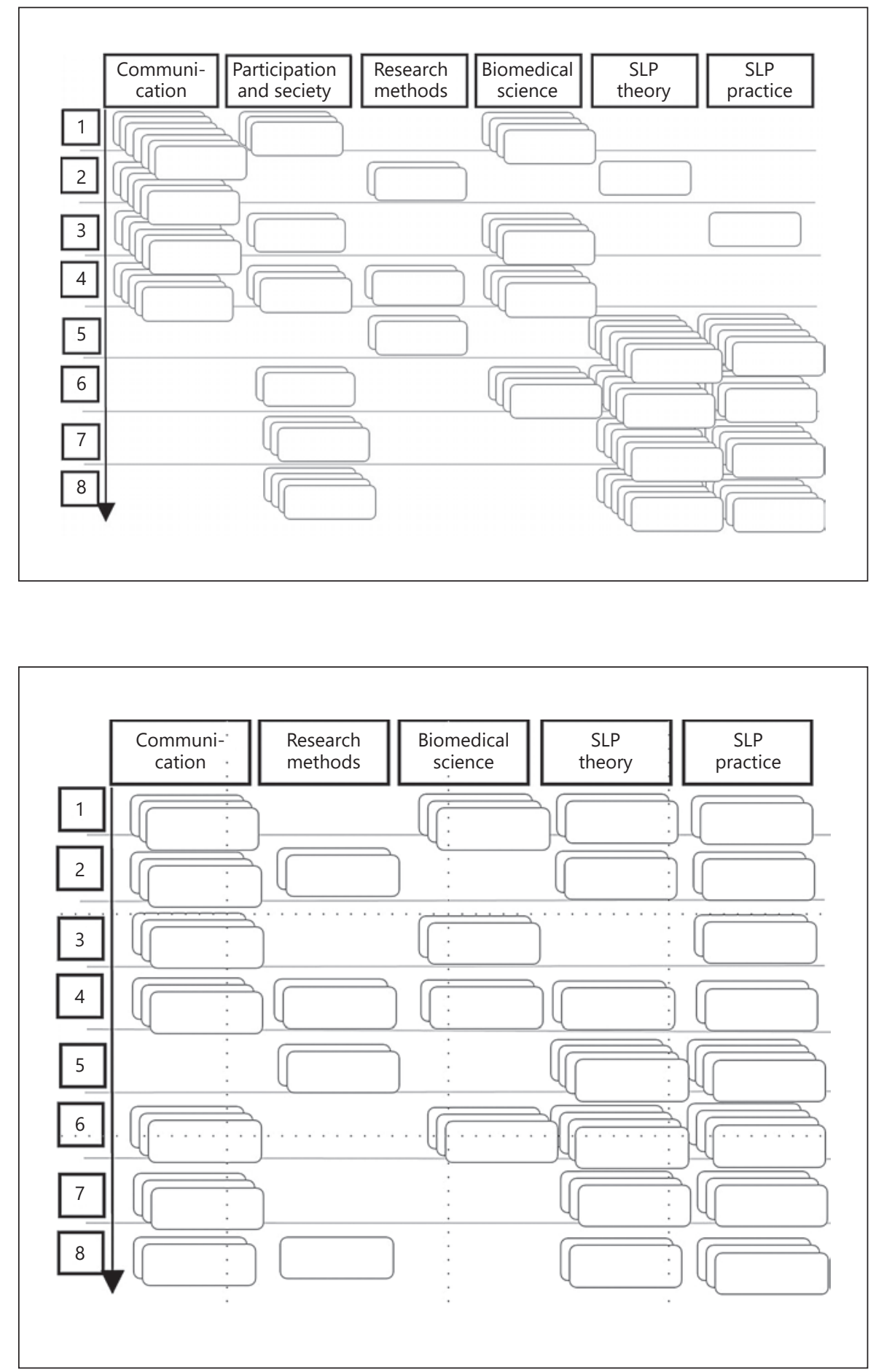

Fig. 2. Schematic illustration of the distribution of learning outcomes in the curriculum after the curricular changes, across the five vertical tracks Communication, Research methods, Medical science, SLP theory and SLP practice, and across the eight semesters of the education programme. Each box represents one learning outcome, with the restriction that the number of stacked boxes never exceeds seven, for readability. suggested learning activities. After this first meeting, the first author revised and refined the curriculum in close collaboration with teacher staff and clinical representatives in smaller constellations. A follow-up meeting with the original group of participants (with minor adjustments) was arranged after 6 months to present and discuss the revised version of the curriculum.

\section{New Curricular Structure}

A schematic illustration of the revised curricular structure is presented in Figure 2. When comparing this figure to the curricular structure presented in Figure 1, two differences can be noted. First, the originally suggested track Participation and Society is absent. This track was removed after discussions with the teacher 
group, as its content could easily be merged into other tracks. Second, in relation to the pre-change curriculum in Figure 1, Figure 2 illustrates a diminished imbalance between the different tracks in the revised curriculum, both horizontally and vertically (for an overview of the course structure of the revised curriculum; see Appendix).

As an example of an effort towards increased vertical integration, one learning outcome in the Communication track involved conducting audio recordings for perceptual and acoustic analyses of voice quality. Discussions between teachers representing both basic phonetic science and clinical research on voice disorders ensured that these early recordings followed the clinical state of the art, e.g., by using comparable equipment and reading manuscripts. A learning outcome for voice assessment could thus be specified already in the first year of studies - thereby connecting fundamental science to clinical application (and providing content in the Theoretical SLP track) in the first year. Additionally, recordings were saved in the students' portfolios, and revisited later in the education programme, to serve as a basis for spiral learning.

In previous evaluations, the Child Observations had been mentioned as one of the strengths of the SLP-KI, with the caveat that these could benefit from integration with other courses. Before the curricular revision, the focus had been on the communicative behaviour and context of the child, as well as on the students' role as observers. Notably, the material documented during the students' observations was not referred to or used in other courses. In the curricular revision, the Child Observations was identified as a platform for both horizontal and vertical integration. For example, recordings of the infant during the first year of studies provide examples to which courses concerning early communication (in the Communication track), documentation (in the Research Methods track) and early communicative assessment (in the SLP Theory track) can refer. This aligns with the theme "The infant," which is specified as a horizontal theme during the second semester (see Appendix). Later activities within the Child Observation stream serve to promote increased professional autonomy. Summarizing their Child Observations and communicating an analysis to parents and first-year students requires students to synthesize theoretical knowledge about children's communicative and feeding development, and to use professional communicative skills to adapt information to different recipients, thus fitting the advanced level of the last year of the curriculum.

In fact, the Child Observations also inspired the overall structure of the curriculum, which - at least partially - follows an agechronological structure. This is reflected in the course overview in the Appendix, where the horizontal themes across the education are presented for each semester. The introductory semester introduces the students to the SLP area and related domains. Compared to the earlier curriculum, the first semester in the new curriculum provides a broader introduction, e.g., by covering not only development up until adulthood, but the entire lifespan, and by providing more content in the SLP Theory and SLP Practice tracks. The second to fifth semesters follow the age-chronological structure. The sixth semester covers conditions that occur irrespective of age, such as voice and fluency disorders, and dysphagia. Finally, the entire last year in the new curriculum provides elective studies at advanced level, including revisiting fundamental science.

Towards an Integrated Curriculum in SLP

\section{Constituent Interviews}

The curricular revision was evaluated by the end of the first semester after the launch of the new curriculum, through semistructured interviews with teachers $(n=8)$, clinical representatives $(n=5)$, first-semester students in the new curriculum $(n=$ $1)$ and in the seventh semester of the earlier curriculum $(n=2)$, and 1 alumna. Student representatives were asked to collect comments and opinions from fellow students. The interviews were conducted by a person who had not been involved in the curricular changes (the second author) to minimize the risk of a positive bias. The following questions were included in the interviews:

1 What do you perceive as strengths in the new curriculum? Please provide examples and rank them.

2 What do you perceive as weaknesses/risks in the new curriculum? Please provide examples and rank them.

3 In what way is the new curriculum an improvement compared to the earlier?

4 In what way is the new curriculum a downgrade compared to the earlier?

5 Do you have any suggestions of how potential risks can be prevented/avoided?

6 Do you see any gaps in the new curriculum?

7 Do you see any overlaps in the new curriculum?

8 Do you have any other suggestions of potential improvements?

When invited, respondents were informed that the curriculum had been revised, but not about the purpose of this revision. A schematic overview of the new curriculum was attached to the invitation (see Appendix). The interviewer recorded responses on paper during the course of the interviews and re-transcribed the responses onto a computer in immediate connection to each interview.

\section{Content Analysis}

A content analysis [20] of the interview responses was conducted by the first (S.S.) and second (K.H.) authors in collaboration. The focus of the analysis was the manifest data, rather than on the latent content of data [see 20]. After having read through the complete record of responses several times to familiarize with the data, the first step of the analysis was data condensation. This step was conducted in an iterative manner, where S.S. suggested collapses of similar responses into generic forms, which K.H. confirmed as long as they reflected her original impression of the responses. For example, the following two original responses to the question "What do you perceive as strengths in the new curriculum?":

Professional development seems to be present throughout the education, which hopefully will enable a more comprehensive view on the profession, as opposed to divided into theory and practice, and so on.

Activities related to professional development are tied together.

were mapped onto the same generic form "Professional development as a coherent stream." After this condensation of data, the two investigators identified mutually exclusive categories, into which responses were sorted. For example, the response "Professional development as a coherent stream" was sorted into the category Integration, together with responses like "Research methodology runs throughout the education." 
The analysis of the interviews was presented and discussed at a meeting with the majority of the respondents (all eight teachers and two of the five clinical representatives) present, allowing the respondents the chance to clarify uncertainties or misunderstandings.

\section{Results}

Five categories were identified in the content analysis of the evaluation interviews: Integration, Course Structure, Implementing Changes, Work-Integrated Learning, and Transition into Practice and Working Life. Each of these categories are described below, with selected quotes presented to illustrate representative statements within each category.

\section{Integration}

Responses categorized as concerning integration related either to formal aspects of curricular structure or to less formal aspects, such as regarding collaboration between teachers across departments. Regarding the more formal aspects, several respondents brought up issues related to the curricular design, mentioning the horizontal themes and vertical tracks as providing structure:

Semester themes are clearer and connected to the courses, making it more lucid and transparent. The education covers many subject areas and risks giving a fragmented impression if it hadn't been for this structuring. (Student, seventh semester)

In the new curriculum, knowledge is expanded and deepened, as you're reminded by the subject tracks all the way. (Teacher)

The curriculum seems to have more of a common thread and is not as compressed as before. (Student, seventh semester)

The use of Child Observation as a means for both horizontal and vertical integration was also recognized:

Using material from the Child Observations also in other courses will prepare the students better for connecting what they see in the child's development to other stuff they read. The theoretical courses will also gain from the students having collected their own material. (Teacher)

Not all responses relating to integration were positive, however. Some respondents expressed concerns regarding all subject areas not being equally integrated in the new curriculum:

Integration of medicine and collaboration with medical representatives hasn't been discussed and considered to the same extent as linguistics and psychology. (Teacher)
Regarding less formal aspects of integration, some respondents highlighted the curriculum development process in terms of collegial collaboration as contributing to increased integration between teachers representing different subject areas:

The development of the new curriculum has provided opportunities to meet more often and to deal with things. As a consequence, we've discovered shortcomings and miscommunication between course directors from different disciplines and moved things forward. (Teacher)

All involved have met and talked, which, in itself, serves to strengthen quality. (Teacher)

\section{Course Structure}

Regarding the new course structure, that is, the division of curricular content into courses, and the ordering of these courses, respondents frequently recognized and accredited the expansion of SLP areas at the expense of foundational science:

SLP has been strengthened; longer courses and more cohesive than before. (Teacher)

Dysphagia is strengthened; could give deeper knowledge than before. (Teacher)

One respondent, however, cautioned that the redistribution of credits may leave insufficient time for crucial prerequisites:

Despite earlier requests from practicing SLPs that students need to be better equipped with grammatical knowledge, this area has instead been downsized. (Teacher)

Some respondents also cautioned that although the restructuring seemed to have strengthened certain areas, it could also, as a side effect, have introduced new gaps:

It might be difficult, when taking the course in dysphagia, to remember what you've learnt about swallowing earlier. The time lapse is large from learning about early communication and feeding disorders. (Clinical representative)

Although the use of the Child Observations as a platform for both vertical and horizontal integration was recognized by many respondents (see above), one respondent saw a risk of the age-chronological structure being too child-focused:

The fact that SLP areas not related to children are introduced late in the education programme may drive away those students who are more interested in other areas than paediatric SLP. (Clinical representative)
Strömbergsson/Holm/Lohmander/ Östberg 


\section{Implementing Changes}

Many respondents recognized that implementation of the curriculum is an ongoing process and touched upon several challenges in this process. A general challenge in identifying and appointing responsibilities emerged frequently, for example:

Everyone are required to take responsibility. It is unclear who is responsible for what; who are concerned? There's a risk that everyone have to think about everything. (Teacher)

All concerned need to take responsibility for getting in touch with each other, for protecting their interests and plan ahead. (Teacher)

Several respondents stressed the need for continued communication to mitigate challenges to successful implementation:

Good communication is needed between the person responsible for the Child Observations and course responsible teachers, so that the collaboration works. (Teacher)

It is important to plan further ahead in time to achieve good coordination, and not just focus on what's going on right now. (Teacher)

Regular meetings with the different departments to promote good contact and collaboration. (Teacher)

\section{Work-Integrated Learning}

Work-integrated learning (WIL) refers to activities where academic learning is integrated with practical application in clinical settings. Regarding the organization of WIL in the revised curriculum, most respondents were positive to the fact that the students' first experience of WIL had been advanced from the fourth semester to the third, as illustrated in the following sample responses:

It is good that students get used to meeting patients; this accelerates their professional development. (Clinical representative)

The earlier WIL may contribute to a more progressive transition into the role of being an SLP. (Alumna)

However, one respondent cautioned that this would raise new challenges for the clinical supervisors:

The early WIL demands more from the supervisors and they need backing to be able to receive and support the student where they are in their learning. (Clinical representative)

Furthermore, concerns were raised regarding the reorganization involving a separation of dysphagia from disorders of speech and language:

Towards an Integrated Curriculum in SLP
Difficult to tease apart dysphagia from speech/language. During the 5th semester, students may have to observe [rather than to practice themselves] because they don't yet have the required dysphagia knowledge. (Clinical representative)

Inpatient care clinics may have difficulties to provide opportunities for the students to encounter patients with language problems. (Clinical representative)

The WIL for the adult population is divided into several periods, which will be difficult to implement. Patients often have several difficulties, and a separation of the WIL periods doesn't reflect a holistic perspective. (Clinical representative)

\section{Transition into Practice and Working Life}

Several respondents commented that the curriculum revision had involved a long-awaited inventorying of learning outcomes and activities related to professional development.

Professional development seems to be present throughout, which hopefully will promote a more holistic view on the profession. (Teacher)

Professional development will be more coherent than before. (Teacher)

Many accredited the suggested course on the seventh semester specifically designed to ease the transition to working life, as exemplified in the following:

The course "Transition to professional autonomy" will serve as a good transfer to working life. (Teacher)

\section{Discussion}

The constituents' responses to the new curriculum of the SLP education programme at Karolinska Institutet indicate that several efforts to strengthen curricular integration specifically between foundational and clinical sciences have had the desired effect, at least in terms of being recognized as an intent in the curriculum. As the curriculum is still being implemented - at the time of writing, the first group of students following the new curriculum are only halfway through their education a more comprehensive evaluation, preferably also including potential effects on the students' learning, is not yet possible. This being said, there are lessons to be learnt from the curricular development process thus far.

First, the horizontal themes and vertical tracks not only guided the restructuring of learning outcomes, they also appeared to serve as a structural skeleton to the respondents, aiding them in recognizing the interrelation 
between courses and streams in the curriculum. Notably, many respondents touched upon "integration," without specifically having been asked about it. Presumably, if the horizontal themes and vertical tracks are also presented to students within the education programme, it may also aid them in making connections between content across subject areas.

Second, challenges to successful implementation were identified, stressing the importance of identifying and appointing responsibilities and continuing discussions across departments as important means of maintaining integration throughout the curriculum. A concern raised before in the context of integrated curricula is that increased integration puts higher demands on teachers to know the curriculum and their role in it [9]. For successful integration, teachers should at least be aware of, and preferably refer to, content of other learning activities and build upon what has been taught before and/or in other disciplines [21]. Providing clear guidelines and support to teachers regarding the context of their contribution, and what to expect from students at a certain level, has been suggested for ensuring such awareness [22]. The concern raised in the present evaluation, that all teachers may not have the time or the motivation to recognize the context in which their contribution appears, reflects a need for defining responsibilities that stretch across course and semester boundaries for supporting teachers with guidelines and monitoring curricular integration. It should be acknowledged, however, that to some, merely being provided with guidelines regarding the context of their contribution may interfere with one's sense of academic freedom [23]. Hence, continued dialogue between teachers across departmental boundaries is important not only for the sake of assuring curricular integration, but also for the sake of preserving teachers' academic freedom. Ideally, the teachers themselves should also be involved in the design of such guidelines.

The evaluation further found some respondents cautioning that new gaps had been introduced related to dysphagia, when students in clinical practicum encounter individuals with dysphagia while not yet having learned to handle such conditions. This is an inevitable issue in clinical practicum; students are likely to encounter individuals with multiple conditions, while still only prepared to address some. On the other hand, the students' experiences from seeing conditions they have not yet studied may be used to advantage when they eventually do. For students following the new curriculum at SLP-KI, encounters with dys- phagia in individuals with communication disorders during the fourth and fifth semesters may actually help in bridging vertical gaps between early introductions to dysphagia and the dysphagia course in the sixth semester.

The curricular revision involved an expansion of SLP areas at the expense of academic credits in foundational sciences. On the positive side, this reinforced previously insufficiently covered areas like dysphagia and reading disorders. On the negative side, however, some respondents cautioned that this left insufficient time for crucial prerequisites in, for example, language structure. Continued evaluation will tell if this caution is warranted.

There are different degrees and types of curricular integration $[8,24]$, and the implemented curriculum does certainly not meet the standards for the "highest" level of integration, transdisciplinary integration [25]. This would require a full dissolution of boundaries between disciplines, place learning in the context of realworld problems, and the integration of knowledge from different traditional subject areas in the mind of the student [25]. While the planning of courses now involves closer collaboration across departmental boundaries, and although teachers representing different subject areas are now more actively involved in the planning and execution of broader courses, and link their contributions to common themes, the boundaries between departments, disciplines and fields of knowledge have not been erased. Still, in a challengingly diverse cross-disciplinary field like SLP, we do consider these steps significant. To SLP educators who strive for increased integration, the changes suggested here may illustrate a viable path to increased curricular integration.

\section{Strengths and Limitations}

Evaluation responses were recorded on paper during the course of the interviews, precluding possibilities of analysing the reliability of the transcriptions. In retrospect, audio documentation should have been preferred. As it stands, the verbatim reading of the responses involves some degree of uncertainty.

It should be acknowledged that in the evaluation interviews, around half of the respondents had also been involved in the curricular change process and were not oblivious of its focus. The collection of student opinions through a few representatives may further have contributed to a favourable bias. Although efforts were made to balance this risk - such as having
60

Folia Phoniatr Logop 2020;72:52-63 DOI: $10.1159 / 000497609$
Strömbergsson/Holm/Lohmander/ Östberg 
an external interviewer conducting the evaluation interviews, and of basing interviews on value-neutral questions not explicitly mentioning the concept of integration - it cannot be ignored. However, the fact that respondents spontaneously provided illustrations of increased integration when being interviewed could be seen as an acknowledgement of this aim having been met.

\section{Future Work}

As alluded to before, the evaluation presented here will need to be complemented with a more comprehensive evaluation when the curriculum has been fully implemented. This is perhaps most critical when evaluating vertical integration. Educators have observed that students' reported confusion early in an education designed by spiral learning resolves over time as topics are revisited [15]. Hence, it is important to bear in mind that students' perception of an integrated curriculum may change during the course of their education. A comprehensive evaluation after the full implementation would also offer the possibility of exploring whether the revised curriculum has addressed the reported workload imbalance in the previous curriculum.

Although the role of employing appropriate assessment methods has been stressed by many medical educators [e.g., 26], this has not been the focus of the curricular changes, and, consequently, nor in the evaluation. Hence, a systematic evaluation of the assessment methods employed in the curriculum, and whether they align with the objectives of the curricular integration, remains another important issue for future work.

\section{Conclusions}

In efforts to increase integration in an education programme, the concepts gaps and overlaps may aid the identification and remediation of specific areas where increased integration is warranted. In an SLP education context, serial child observations running through the curriculum may provide a platform for both horizontal and vertical integration, serving to link between contents in different courses and between earlier and later parts of the education. In order to ensure and maintain successful curricular integration, clear responsibilities are needed, preferably stretching across course and semester boundaries. Although applied to an SLP education context, these concepts and observa- tions are generic and potentially useful for any medical educator striving towards increased curricular integration.

\section{Acknowledgements}

Our sincere thanks to all students and staff members for contributing to this work through their participation in surveys and interviews, but also during discussions in meetings concerned with the curricular development.

\section{Statement of Ethics}

Data was retrieved from course evaluation surveys and exit polls performed according to guidelines at Karolinska Institutet. Agreed participation is implied by respondents completing and submitting the surveys anonymously. Interviews were carried out with staff and students who agreed to participate and followed ethical principles. No personal identifying information was collected, nor was any private or sensitive information elicited. According to the Swedish Ethical Review Act (2003:460) vetting by an ethical review board is thus not required.

\section{Disclosure Statement}

The authors have no conflicts of interest to declare.

\section{Funding Sources}

There is no funding to report.

\section{Author Contributions}

S.S. was responsible for the concept and design of the study, data collection and analysis, and for several drafts of the paper. K.H. was responsible for conducting the evaluation interviews and for analysing the responses in collaboration with S.S. P.Ö. and A.L. were responsible for overseeing the concept and design of the study and contributed to the interpretation of the results and to the writing of the paper. All authors read and approved the final paper for publication.

\section{Appendix}

New Curriculum Overview

The course structure of the revised curriculum, as presented to the interview respondents. Vertical tracks are represented in the top panel, and horizontal themes in the panel to the left. 


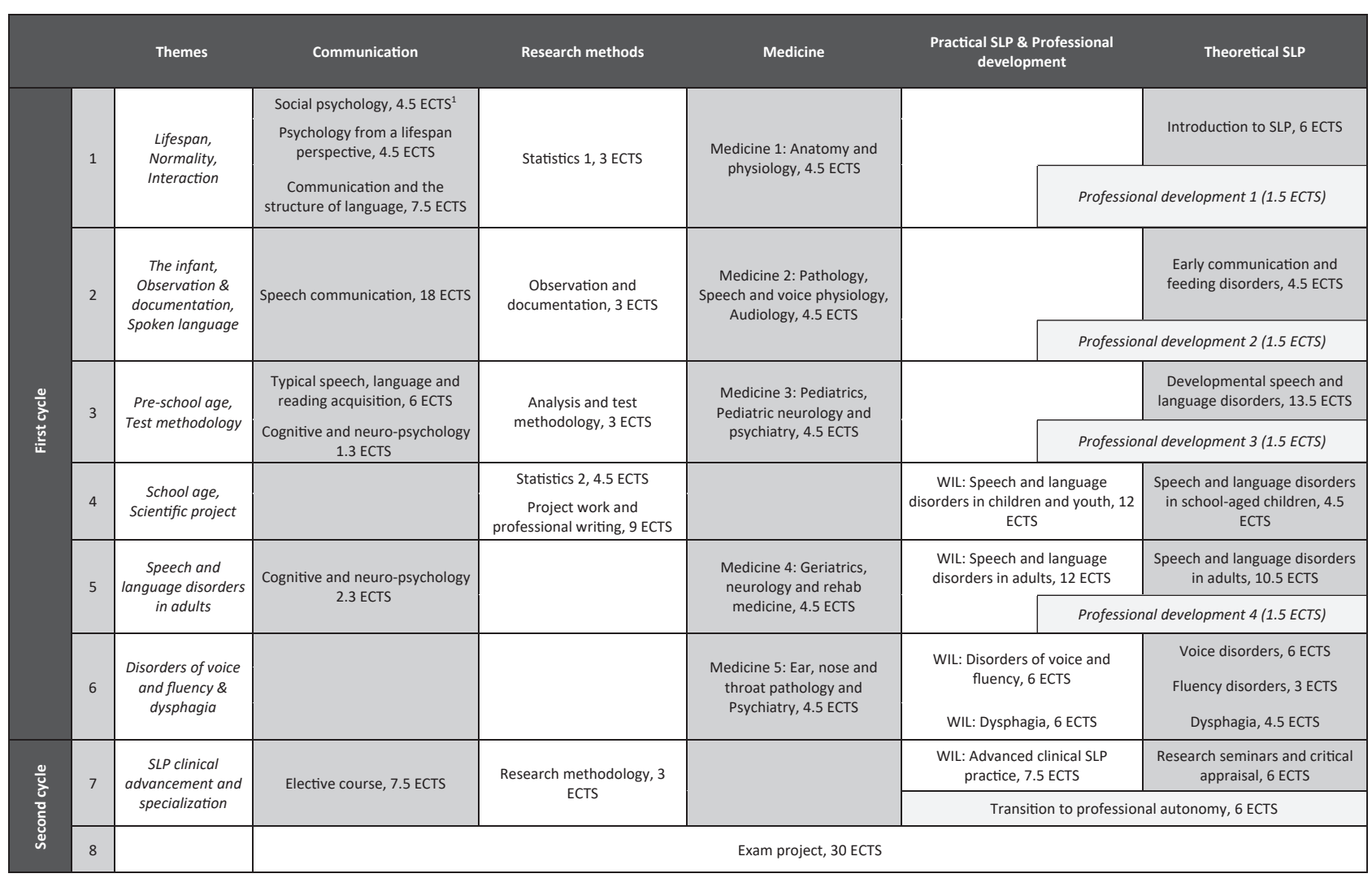

${ }^{1}$ European Credit Transfer and Accumulation System (ECTS) course credits; 60 ECTS correspond to 1 year of academic studies.

\section{References}

1 American Speech-Language-Hearing Association. Scope of practice in speech-language pathology [Scope of Practice], 2016. Available from: www.asha.org/policy/.

2 International Association of Logopedics and Phoniatrics Education Committee. Revised IALP education guidelines (September 1, 2009): IALP Guidelines for initial education in speech-language pathology. Folia Phoniatr Logop. 2010;62(5):210-6.

3 Söderpalm E. Education of speech-language pathologists around the world: the Scandinavian experience. Folia Phoniatr Logop. 2006; 58(1):59-63.

4 Bandiera G, Boucher A, Neville A, Kuper A, Hodges B. Integration and timing of basic and clinical sciences education. Med Teach. 2013 May;35(5):381-7.

5 Kogan JR, Shea JA. Course evaluation in medical education. Teach Teach Educ. 2007;23(3): 251-64.

6 Brauer DG, Ferguson KJ. The integrated curriculum in medical education: AMEE Guide No. 96. Med Teach. 2015 Apr;37(4):312-22.
7 Brackenbury T, Folkins JW, Ginsberg SM. Examining educational challenges in communication sciences and disorders from the perspectives of signature pedagogy and reflective practice. Contemp Issues Commun Sci Disord. 2014;41:70-82.

8 Drake S, Burns R. Meeting Standards through Integrated Curriculum. Alexandria, Vancouver: Association for Supervision and Curriculum Development; 2004.

9 Dahle LO, Brynhildsen J, Behrbohm Fallsberg M, Rundquist I, Hammar M. Pros and cons of vertical integration between clinical medicine and basic science within a problem-based undergraduate medical curriculum: examples and experiences from Linköping, Sweden. Med Teach. 2002 May;24(3):280-5.

10 Whitehill TL, Bridges S, Chan K. Problembased learning (PBL) and speech-language pathology: a tutorial. Clin Linguist Phon. 2014 Jan-Feb;28(1-2):5-23.

11 Beane JA. Curriculum integration and the disciplines of knowledge. Phi Delta Kappan. 1995;76:616-22.
12 Vidic B, Weitlauf HM. Horizontal and vertical integration of academic disciplines in the medical school curriculum. Clin Anat. 2002 May;15(3):233-5.

13 Bruner J. The Process of Education. Cambridge (MA): Harvard University Press; 1960.

14 Davis MH, Harden RM. Planning and implementing an undergraduate medical curriculum: the lessons learned. Med Teach. 2003 Nov;25(6):596-608.

15 Coelho C, Moles D. Student perceptions of a spiral curriculum. Eur J Dent Educ. 2016 Aug; 20(3): 161-6. https://doi.org/10.1111/ eje. 12156.

16 Howard SJ, Heselwood BC. Learning and teaching phonetic transcription for clinical purposes. Clin Linguist Phon. 2002 Jul-Aug; 16(5):371-401.

17 Hill AE, Davidson BJ, McAllister S, Wright J, Theodoros DG. Assessment of student competency in a simulated speech-language pathology clinical placement. Int J Speech Lang Pathol. 2014 Oct;16(5):464-75. 
18 Howard S. Clinical Linguistics for speech and therapy education [accessed 2017 Feb 17]. Southampton: Centre for Languages, Linguistics \& Area Studies, University of Southampton; 2002. https://www.llas.ac.uk/resources/ gpg/406.html.

19 Department of Human Communication Sciences, University of Sheffield; 2016 [accessed 2016 Jan 13]. https://www.sheffield.ac.uk/ hcs/prospective_ug/bmedsci.

20 Vaismoradi M, Turunen H, Bondas T. Content analysis and thematic analysis: implications for conducting a qualitative descriptive study. Nurs Health Sci. 2013 Sep;15(3):398-405.

21 Malik AS, Malik RH. Twelve tips for developing an integrated curriculum. Med Teach. 2011;33(2):99-104.

22 O'Regan A, Culhane A, Dunne C, Griffin M, McGrath D, Meagher D, et al. Integrating postgraduate and undergraduate general practice education: qualitative study. Educ Prim Care. 2013 May;24(3):158-64.

23 Edwards R, Crosling G, Lim N. Organizational Structures for International Universities:
Implications for Campus Autonomy, Academic Freedom, Collegiality, and Conflict. J Stud Int Educ. 2014 May;18(2):180-94.

24 Lam CC, Alviar-Martin T, Adler SA, Sim JB. Curriculum integration in Singapore: Teachers perspectives and practice. Teach Teach Educ. 2013;31:23-34.

25 Harden RM. The integration ladder: a tool for curriculum planning and evaluation. Med Educ. 2000 Jul;34(7):551-7.

26 Epstein RM. Assessment in medical education. N Engl J Med. 2007 Jan;356(4):387-96. 